\title{
OPEN Reliability and usefulness
}

\section{of the single leg heel raise balance test in patients with chronic ankle instability}

\author{
Jin Hyuck Lee ${ }^{1}$, Hae Woon Jung ${ }^{3}$, Taek Sung Jung ${ }^{4} \&$ Woo Young Jang ${ }^{1,2 \bowtie}$
}

We aimed to analyze the differences in static (including conventional and modified [single-leg heelraise balance]) and dynamic postural stability and muscle endurance between patients with chronic ankle instability (CAI) and healthy controls, and to determine the reliability and usefulness of the single-leg heel-raise balance test in patients with CAI. In total, 26 patients with CAI and 26 healthy controls were enrolled. Postural stability was assessed using a postural stabilometry system. Muscle endurance was measured in dorsiflexion and plantarflexion using an isokinetic device. Modified static postural stability $(P<0.001)$ and dynamic postural stability $(P<0.001)$ were significantly poorer in the affected ankles of patients with CAI than in the controls. Plantarflexion endurance was significantly lower in the affected ankles of the patients with CAI than in the controls $(P=0.023)$. Modified static postural stability significantly correlated with plantarflexion endurance in both groups (CAl group: $r=-0.470, P=0.015$; healthy controls group: $r=-0.413, P=0.036)$. Plantarflexion endurance was a significant risk factor for modified static postural stability in both the CAI group $\left(R^{2}=0.221, P=0.015\right)$ and healthy controls $\left(R^{2}=0.170, P=0.036\right)$. Given the reliability of the modified static postural stability test, clinicians and therapists should consider using it to assess improvements in postural stability and muscle endurance in patients with CAI before and after rehabilitation.

Ankle sprains are commonly experienced during sports activities, and lateral ankle sprain occurs with a particularly high frequency ${ }^{1,2}$. Lateral ankle sprain can cause chronic ankle instability (CAI $)^{3,4}$ due to ligamentous complex injury, muscle weakness, and lack of proprioception and neuromuscular control ${ }^{5,6}$. Therefore, clinicians and therapists recommend specific rehabilitation to recover strength, proprioception, and neuromuscular control in patients with $\mathrm{CAI}^{4}$.

As most previous studies have reported a lack of proprioception in patients with $\mathrm{CAI}^{4,5,7-10}$, the single-leg balance test has been used to determine the prognosis of functional recovery, including proprioception, before and after treatment such as surgery and conservative rehabilitation in patients with CAI. However, this balance test comprises static and dynamic postural stability tests ${ }^{8,11,12}$. It has been reported that static ${ }^{12,13}$ and dynamic $c^{8,12-14}$ postural stability deficits are the most important factors to consider in the treatment of patients with CAI. Furthermore, a previous study reported that calf muscle endurance was lower in patients with CAI who underwent rehabilitation than in those with CAI who underwent the modified Broström procedure ${ }^{9}$; thus, it is an important factor in the treatment of these patients. To our knowledge, only one previous study has evaluated calf muscle strength using the heel-raise test in patients with $\mathrm{CAI}^{15}$. The heel-raise test is commonly used to assess calf muscle endurance ${ }^{16-19}$ and is cost-effective and highly reliable ${ }^{18}$. However, to our knowledge, no studies have yet examined the single-leg heel-raise balance test (modified static postural stability test) as a combination of the single-leg balance and heel-raise tests in patients with CAI and healthy controls. In particular, this test may be considered an important evaluation method to confirm the existing problems of patients with CAI because it can simultaneously evaluate the single-leg balance ability and calf muscle endurance. Moreover, whether the modified static postural stability test is more effective than the conventional postural stability test for assessing postural stability in patients with CAI remains unknown.

${ }^{1}$ Department of Sports Medical Center, Korea University College of Medicine Anam Hospital, Seoul, Korea. ${ }^{2}$ Department of Orthopedic Surgery, College of Medicine, Korea University, 73, Inchon-ro, Seongbuk-gu, Seoul 02841, Republic of Korea. ${ }^{3}$ Department of Pediatrics, Kyung Hee University Medical Center, Seoul, South Korea. ${ }^{4}$ TMX Limited, Seoul, Republic of Korea. ${ }^{\circledR}$ email: opmanse@gmail.com 
Therefore, this study aimed to analyze the differences in static postural stability, including conventional and modified static postural stability, dynamic postural stability, and muscle endurance between patients with CAI and healthy controls, and to investigate the relationship between static postural stability and muscle endurance, thus determining the reliability and usefulness of the modified static postural stability test in patients with CAI. We hypothesized that static and dynamic postural stability and muscle endurance were poorer in patients with CAI than in healthy controls, and that modified static postural stability may be significantly correlated with muscle endurance.

\section{Methods}

Study design and patient enrollment. The study was approved by the Institutional Review Board of the Korea University Anam Hospital (IRB No: 2019AN0397), and informed consent was obtained from all participants prior to the commencement of this study. All studies were conducted in accordance with the relevant guidelines and regulations.

Initially, 47 patients with CAI receiving rehabilitation from October 2019 were included in this study. All patients underwent plain stress radiography and physical examination and were evaluated by two orthopedic surgeons. Any disagreements were resolved by consensus. The inclusion criteria were patients with CAI with mechanical ankle instability due to lateral ankle sprain (the presence of a talar tilt $>9^{\circ}$ and a difference between sides $>3^{\circ}$ or $3 \mathrm{~mm}$ in anterior drawer $)^{8}$ with a history of constant symptoms and repetitive sprains for 12 months prior to the study ${ }^{20,21}$. Patients with bilateral ankle sprains, deltoid ligament injuries, and acute ankle sprains were excluded. We also excluded patients with concomitant injuries causing knee and lower back pain as this would affect the postural stability test. In total, 26 healthy controls were selected from our database of volunteers with no history of sprains on either ankle for participation in this study. After excluding 21 patients, 26 patients with CAI and 26 healthy controls were enrolled in this study.

Assessment of postural stability. The postural stability test was performed using the Biodex Stability System (BSS; Biodex Medical Systems, Inc., Shirley, NY, USA), which comprises static and dynamic postural stability tests. The static postural stability test uses a fixed platform, whereas the dynamic postural stability test uses a mobile platform. In the present study, static postural stability consisted of conventional static and modified static postural stability tests. The conventional static postural stability test (Fig. 1A) was conducted in a singleleg stance with the knee straight on a fixed platform ${ }^{8}$, whereas the modified static postural stability test (Fig. 1B) was conducted with the knee straight while the patient maintained a heel lift of approximately $2-3 \mathrm{~cm}$ on a fixed platform ${ }^{22}$. During the modified static postural stability test, one physical therapist continuously instructed the participants to maintain an approximately $2-3 \mathrm{~cm}$ heel lift using a stick ruler, and the test was terminated if the posture could not be maintained, or the proper heel lift was not performed. Dynamic postural stability was evaluated in a single-leg stance on a mobile platform ranging from level 12 (stable platform) to level 1 (unstable platform), with the stability level automatically declining every $1.66 \mathrm{~s}$, with a $20^{\circ}$ tilt and $360^{\circ}$ platform rotation ${ }^{8}$. All participants were barefoot on the platform during the measurements, with the device screen covered to minimize visual compensation, wherein they performed two trials for $20 \mathrm{~s}$ each leg. A greater stability index (overall stability index [OSI], degree) is indicative of poor postural stability.

Assessment of muscle endurance. The muscle endurance test (concentric-contraction mode) was evaluated in dorsiflexion and plantarflexion in a semi-seated position with $20^{\circ}$ knee flexion using a quantified isokinetic device. Total work $(\mathrm{J})$ was considered to represent muscle endurance and was defined as the sum of all torque curves during the 15 repetitions of dorsiflexion and plantarflexion at an angular velocity of $120^{\circ} / \mathrm{s}^{9,23}$.

Sample size estimation and statistical analysis. Based on the results of previous studies on postural stability in patients with $\mathrm{CAI}^{8,9}$, a difference of $>0.5$ in the OSI between the two groups was considered to be clinically significant. A priori power analysis was performed, with a significance level of 0.05 , and a power of 0.8 , to determine the sample size. According to the effect size (Cohen's d: 1.056) calculated from the results of a pilot study involving 5 ankles in each group, 16 ankles in each group would be required to identify a clinically meaningful difference between the two groups. The power of this study was 0.825 .

Student's $t$-test was used to compare the differences in the conventional static and modified static postural stability, dynamic postural stability, and muscle endurance between the two groups. To determine whether a continuous variable followed a normal distribution, the Shapiro-Wilk test was used. Correlations between conventional static and modified static postural stability and muscle endurance were assessed using Pearson's correlation coefficients. Regression analysis was performed using the significant variables of the Pearson's correlation coefficients. Cohen's d was calculated to examine the effect of statistical differences and was classified as weak $(<0.5)$, moderate $(0.5-0.79)$, or large $(>0.8)^{24}$. Statistical analysis was performed using SPSS (SPSS for software version 21.0; IBM Inc., Chicago, IL, USA); P values $<0.05$ were considered statistically significant.

\section{Results}

Demographic data of the enrolled patients and healthy controls are summarized in Table 1; there were no significant differences between the two groups.

Reliability of the static postural stability test. To quantify the test-retest reliability of the conventional static and modified static postural stability, intraclass correlation coefficients (ICC) were calculated for two trials in each group performed by one physical therapist. The test-retest reliability of the conventional static and modi- 


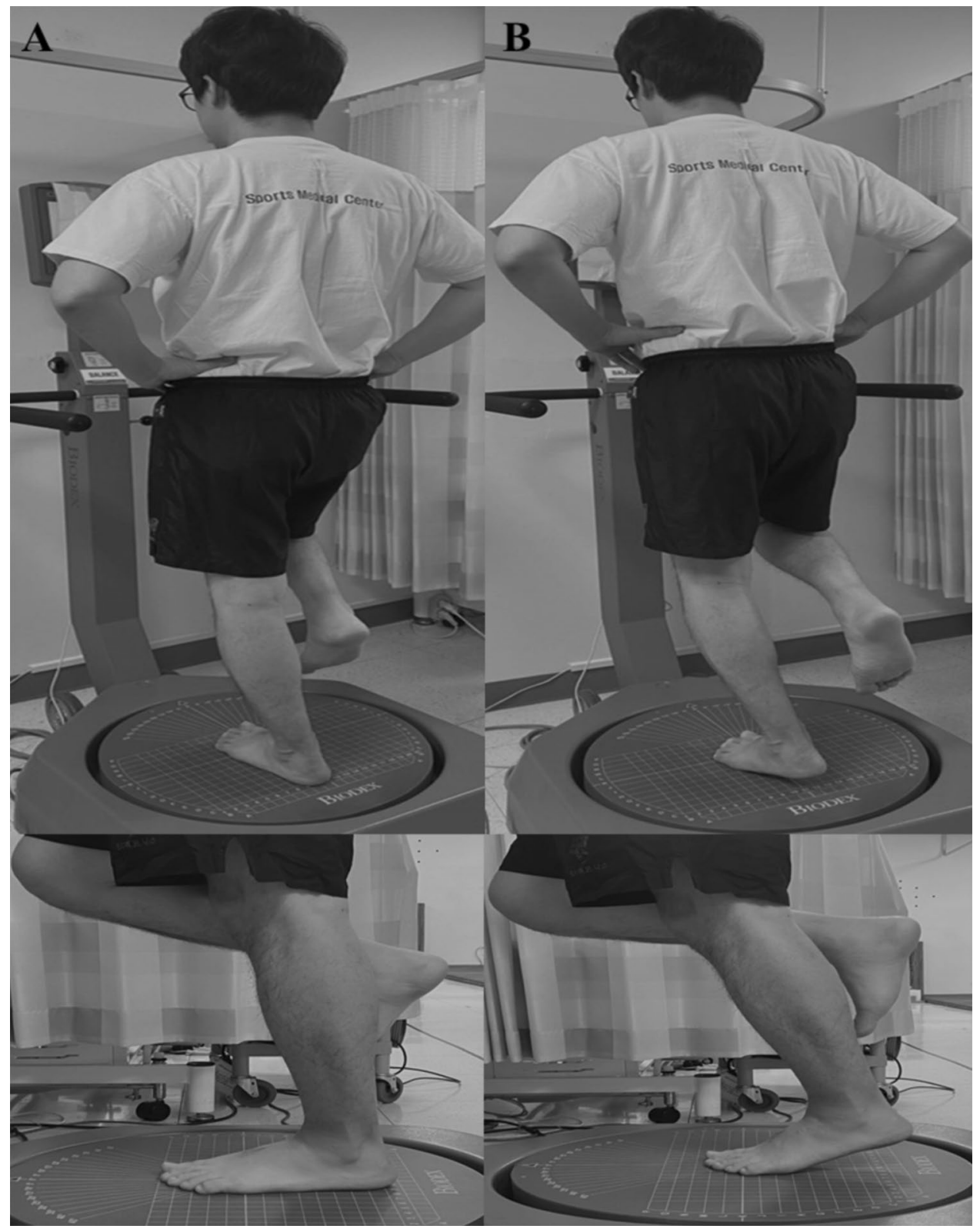

Figure 1. Static postural stability test position. The conventional static postural stability test (a) and modified static postural stability test (b).

\begin{tabular}{|l|l|l|l|l|}
\hline & CAI group & Healthy control group & $P$-value & Effect size \\
\hline Sample size & 26 & 26 & & \\
\hline Sex (male/female) & $17 / 9$ & $20 / 6$ & 0.341 & \\
\hline Age (years), mean (SD) & $25(6.9)$ & $26(5.9)$ & 0.563 & -0.077 \\
\hline Height $(\mathrm{cm})$, mean (SD) & $171(7.0)$ & $168(9.1)$ & 0.085 & 0.181 \\
\hline Weight $(\mathrm{kg})$, mean (SD) & $75(14.7)$ & $73(12.9)$ & 0.512 & 0.072 \\
\hline BMI $\left(\mathrm{kg} / \mathrm{m}^{2}\right)$, mean (SD) & $25(4.1)$ & $26(3.8)$ & 0.770 & -0.125 \\
\hline Sports and activity, n (low:high) & $7 / 19$ & $11 / 15$ & 0.462 & \\
\hline
\end{tabular}

Table 1. Demographic data of the patients with CAI and healthy control subjects. CAI chronic ankle instability,; SD standard deviation. 


\begin{tabular}{|c|c|c|c|c|c|c|}
\hline & \multicolumn{3}{|c|}{ Affected ankles } & \multicolumn{3}{|c|}{ Unaffected ankles } \\
\hline & CAI group & Healthy control group & $p$-value & CAI group & Healthy control group & $p$-value \\
\hline $\begin{array}{l}\text { Modified static } \\
\text { postural stability, mean } \\
\text { (SD) }\end{array}$ & $2.7(0.9)$ & $1.7(0.4)$ & \multirow{3}{*}{$0.000^{\mathrm{a}}$} & $1.6(0.5)$ & $1.6(0.5)$ & \multirow{3}{*}{0.857} \\
\hline$M D,(95 \% C I)$ & \multicolumn{2}{|l|}{$1.0,(0.6,1.3)$} & & \multicolumn{2}{|c|}{$0,(-0.2,0.3)$} & \\
\hline Cohen's d & \multicolumn{2}{|l|}{1.43} & & \multicolumn{2}{|l|}{0} & \\
\hline $\begin{array}{l}\text { Conventional static } \\
\text { postural stability, } \\
\text { mean (SD) }\end{array}$ & $1.2(0.3)$ & $1.0(0.4)$ & \multirow{3}{*}{0.607} & $1.1(0.4)$ & $1.0(0.4)$ & \multirow{3}{*}{0.113} \\
\hline$M D,(95 \% C I)$ & \multicolumn{2}{|l|}{$0.2,(0,0.3)$} & & \multicolumn{2}{|c|}{$0.1,(-0.1,0.3)$} & \\
\hline Cohen's $d$ & \multicolumn{2}{|l|}{0.56} & & \multicolumn{2}{|c|}{0.25} & \\
\hline $\begin{array}{l}\text { Dynamic postural } \\
\text { stability, mean (SD) }\end{array}$ & $2.8(1.4)$ & $1.3(0.7)$ & \multirow{3}{*}{$0.000^{\mathrm{a}}$} & $1.4(0.5)$ & $1.2(0.5)$ & \multirow{3}{*}{0.168} \\
\hline$M D,(95 \% C I)$ & \multicolumn{2}{|l|}{$1.5,(0.9,2.1)$} & & $0.2,(0,0.5)$ & & \\
\hline Cohen's d & \multicolumn{2}{|l|}{1.35} & & \multicolumn{2}{|l|}{.39} & \\
\hline $\begin{array}{l}\text { Dorsiflexion endur- } \\
\text { ance, mean (SD) }\end{array}$ & $93(49.3)$ & $110(41.3)$ & \multirow{3}{*}{0.198} & $99(37)$ & $115(28.3)$ & \multirow{3}{*}{0.086} \\
\hline$M D,(95 \% C I)$ & \multicolumn{2}{|c|}{$-17,(-41.8,8.9)$} & & $-16,(-34.3$ & 2.4) & \\
\hline Cohen's $d$ & \multicolumn{2}{|l|}{-0.37} & & \multicolumn{2}{|l|}{-0.48} & \\
\hline $\begin{array}{l}\text { Plantarflexion endur- } \\
\text { ance, mean (SD) }\end{array}$ & $235(68.1)$ & $280(71)$ & \multirow{3}{*}{$0.023^{\mathrm{a}}$} & $279(134)$ & $291(80)$ & \multirow{3}{*}{0.994} \\
\hline$M D,(95 \% C I)$ & \multicolumn{2}{|c|}{$-45,(-83.9,-6.4)$} & & \multicolumn{2}{|c|}{$-2,(-61.9,61.4)$} & \\
\hline Cohen's d & \multicolumn{2}{|l|}{-0.64} & & -0.10 & & \\
\hline
\end{tabular}

Table 2. Modified static postural stability, conventional static postural stability, dynamic postural stability, and muscle endurance in patients with CAI and healthy controls. Bold means statistically significant between groups. Postural stability (degree) and muscle endurance $(\mathrm{J})$ are expressed as mean \pm standard deviation at $120^{\circ}$ s. CAI chronic ankle instability,; $M D$ mean difference,; $C I$ confidence interval,; SD standard deviation.

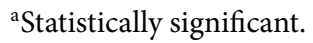

fied static postural stability tests was acceptable in the patients with CAI and healthy controls (ICC $=0.87$ and ICC $=0.91$ for the conventional static test; ICC $=0.80$ and ICC $=0.86$ for the modified static test, respectively).

Postural stability test. In the modified static postural stability (single-leg heel-raise balance) and dynamic postural stability tests, the OSI was significantly higher in the affected ankles of patients with CAI than in healthy controls (modified static: $2.7 \pm 0.9^{\circ}$ vs. $1.7 \pm 0.4^{\circ}, P<0.001$, effect size [Cohen's d] $=1.43$; dynamic: $2.8 \pm 1.4^{\circ}$ vs. $1.3 \pm 0.7^{\circ}, P<0.001$, effect size [Cohen's d] $=1.35$ ). There were no significant differences between the two groups in terms of either the conventional static postural stability test or the unaffected ankles $(P>0.05$, Table 2$)$.

Muscle endurance test. Plantarflexion endurance was significantly lower in the affected ankles of the patients with CAI than in the healthy controls ( $235 \pm 68.1 \mathrm{~J}$ vs. $280 \pm 71 \mathrm{~J}, P=0.023$, effect size [Cohen's d] $=-0.64)$, but there was no significant difference between the unaffected ankles and the healthy controls $(P>0.05$, Table 2$)$. The dorsiflexion endurance test showed no significant differences between the affected and unaffected ankles in the CAI group and healthy controls $(P>0.05$, Table 2$)$.

Correlations between static postural stability and muscle endurance. The correlations between conventional static and modified static postural stability and muscle endurance are shown in Table 3 . There was a significant negative correlation between modified static postural stability and plantarflexion endurance $(\mathrm{r}=-0.470, P=0.015)$, but not between the conventional static postural stability and dorsiflexion endurance $(P>0.05)$ in the affected ankles of patients with CAI. In healthy controls, there was a significant negative correlation between modified static postural stability and plantarflexion endurance $(\mathrm{r}=-0.413, P=0.036$ for the assessment of the affected ankles; $\mathrm{r}=-0.433, P=0.027$ for the assessment of the unaffected ankles), but not between conventional static postural stability and dorsiflexion endurance $(P>0.05)$. Regression analysis revealed that plantarflexion endurance was a significant risk factor for modified static postural stability in both the CAI group $\left(\mathrm{R}^{2}=0.221, P=0.015\right.$, Fig. $\left.2 \mathrm{~A}\right)$ and healthy controls $\left(\mathrm{R}^{2}=0.170, P=0.036\right.$, Fig. $\left.2 \mathrm{~B}\right)$.

\section{Discussion}

The most important result of the present study was that the modified static postural stability (single-leg heelraise balance), dynamic postural stability, and plantarflexion endurance significantly decreased in the affected ankles of the patients with CAI compared with healthy controls. Furthermore, modified static postural stability showed statistically significant correlations with plantarflexion endurance.

In previous studies, dynamic but not static postural stability was decreased in the affected ankles of patients with $\mathrm{CAI}^{9,11,25}$. In the present study, however, modified static postural stability was significantly decreased in 


\begin{tabular}{|c|c|c|c|c|c|c|c|c|}
\hline \multirow[b]{3}{*}{ Parameters } & \multicolumn{4}{|l|}{ CAI group } & \multicolumn{4}{|c|}{ Healthy control group } \\
\hline & \multicolumn{2}{|l|}{ Affected ankles } & \multicolumn{2}{|l|}{ Unaffected ankles } & \multicolumn{2}{|c|}{ Affected ankles } & \multicolumn{2}{|l|}{ Unaffected ankles } \\
\hline & $\begin{array}{l}\text { Modified static } \\
\text { postural stability }\end{array}$ & $\begin{array}{l}\text { Conventional } \\
\text { static postural } \\
\text { stability }\end{array}$ & $\begin{array}{l}\text { Modified static } \\
\text { postural stability }\end{array}$ & \begin{tabular}{|l|} 
Conventional \\
static postural \\
stability
\end{tabular} & $\begin{array}{l}\text { Modified static } \\
\text { postural stability }\end{array}$ & \begin{tabular}{|l|} 
Conventional \\
static postural \\
stability
\end{tabular} & $\begin{array}{l}\text { Modified static } \\
\text { postural stability }\end{array}$ & $\begin{array}{l}\text { Conventional } \\
\text { static postural } \\
\text { stability }\end{array}$ \\
\hline \multicolumn{9}{|c|}{ Dorsiflexion endurance } \\
\hline $\mathrm{PCC}(\mathrm{r})$ & -0.051 & -0.072 & -0.131 & -0.029 & 0.218 & 0.120 & -0.132 & 0.124 \\
\hline P value & 0.804 & 0.727 & 0.523 & 0.888 & 0.284 & 0.561 & 0.520 & 0.545 \\
\hline \multicolumn{9}{|c|}{ Plantarflexion endurance } \\
\hline $\mathrm{PCC}(\mathrm{r})$ & -0.470 & -0.354 & -0.223 & -0.045 & -0.413 & -0.107 & -0.433 & 0.357 \\
\hline P value & $0.015^{\mathrm{a}}$ & 0.076 & 0.274 & 0.826 & $0.036^{\mathrm{a}}$ & 0.603 & $0.027^{\mathrm{a}}$ & 0.074 \\
\hline
\end{tabular}

Table 3. Correlations between modified static postural stability, conventional static postural stability, and muscle endurance. Bold means statistically significant between groups. PCC Pearson's correlation coefficient, CAI chronic ankle instability. ${ }^{\text {a }}$ Statistically significant.
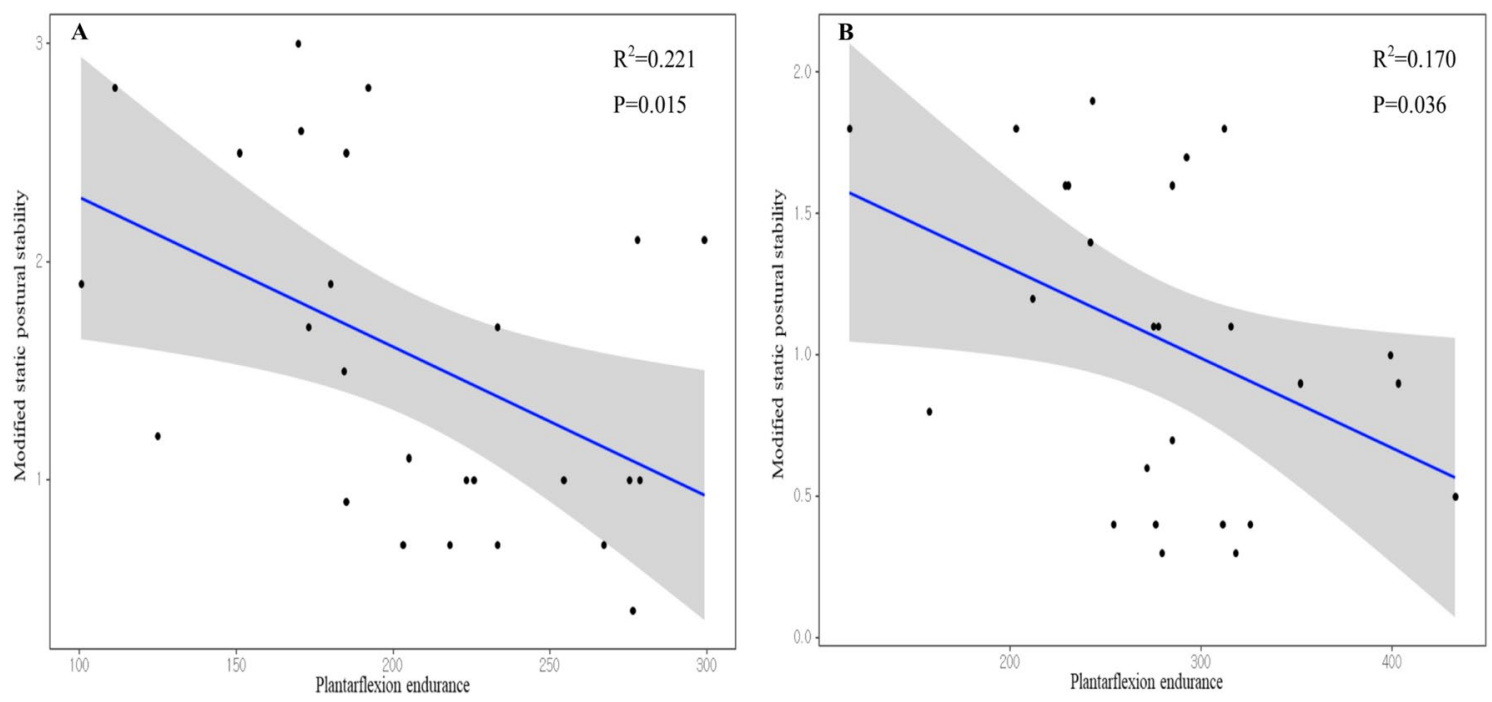

Figure 2. Plots show correlations between the modified static postural stability and plantarflexion endurance in CAI group (a) and healthy control group (b).

the affected ankles of patients with CAI compared with healthy controls. This result may be explained by differences in the talocrural joint stability. The lateral ankle ligament complex, including the anterior talofibular ligament and the calcaneofibular ligament, plays a significant role in talocrural joint stability ${ }^{1,2}$, while talocrural joint instability due to lateral ankle ligament injury can affect postural stability ${ }^{5,8,13}$. The modified static postural stability test, which includes plantarflexion, was performed in the single-leg heel-raise position which decreases the stability of the talocrural joint and reinforces the stabilization of the talocrural joint by the ligamentous complex ${ }^{26}$. However, the conventional static postural stability test was performed in either neutral or dorsiflexion positions, both of which increase the stability of the talocrural joint and represent the locked position of the talocrural joint ${ }^{26,27}$. Although the modified static postural stability test assesses postural stability on a fixed platform, this test position may evaluate postural stability deficits owing to the increased instability of the talocrural joint in the affected ankles of patients with CAI. However, the static postural stability test was found to have a lower reliability ${ }^{25,28,29}$ and an inability to reflect the actual activities of daily living compared with the dynamic postural stability test ${ }^{9,29}$. Nevertheless, compared to the conventional static postural stability test, the modified static postural stability test may more effectively assess postural instability due to the decreased stability of the talocrural joint in patients with CAI.

In previous studies, the repeated heel-raise test was used to assess plantarflexion endurance ${ }^{19,30}$, which was reported to be lower in patients with $\mathrm{CAI}^{15,31,32}$, in line with our findings. In the present study, however, plantarflexion endurance was significantly correlated with the modified static postural stability test in patients with CAI. Although the reasons for this result are unclear, one possible reason may be the similar positioning of the ankle joint during testing. In the present study, both the plantarflexion endurance and modified static postural stability tests were performed with the ankle in plantar flexion, which may increase the micro-damage to the injured lateral ligamentous complex, thereby causing pain and resulting in the loss of muscle endurance and postural stability. Tabrizi et al. ${ }^{33}$. and Vitale and Fallat ${ }^{34}$ reported that the plantarflexion position may lead to an increased incidence of lateral ankle sprains. Moreover, previous studies on patients with $\mathrm{CAI}^{35-37}$ reported that ankle ligament deficits have been reported to lead to weaknesses in reflexive muscle contraction. Another 
potential reason for this result may be the impact of midfoot stability. The subtalar joint is in an inverted position in the plantar flexion position of the ankle joint, resulting in increased midfoot stability. Park et al. ${ }^{15}$. reported that midfoot stability may directly impact postural stability, which may indicate that decreased plantarflexion endurance affects the modified static postural stability test more significantly than it affects the other postural stability tests in patients with CAI. In the present study, statistically significant correlations between plantarflexion endurance and modified static postural stability were also demonstrated in healthy controls. Further investigation of patients with CAI without decreased plantarflexion endurance is necessary to assess the accuracy and efficacy of the modified static postural stability test and to clarify the results of the present study.

This study has several limitations. First, core muscle strength was not evaluated in this study, since Kibler et $a .^{38}$. reported that core muscles play an important role in postural control. Second, we did not measure eccentric plantarflexion strength, although previous studies have reported that eccentric plantarflexion endurance significantly influences postural control ${ }^{39,40}$. However, Hubbard et al. ${ }^{41}$. reported that the concentric plantarflexion strength deficit was significantly greater in patients with CAI, which may also affect postural control. Therefore, the use of concentric and eccentric strengthening exercises for postural stability after rehabilitation in patients with CAI should be investigated. In conclusion, given its apparent reliability in assessing static postural stability and plantarflexion endurance, clinicians and therapists should consider using the single-leg heel-raise balance test to gauge improvements in postural stability and muscle endurance in patients with CAI before and after rehabilitation.

\section{Data availability}

All data generated or analyzed during the current study will not be disclosed due to the policy of the Korea University Anam Hospital Research Ethics Board.

Received: 25 March 2021; Accepted: 17 September 2021

Published online: 13 October 2021

\section{References}

1. Bell, S. J., Mologne, T. S., Sitler, D. F. \& Cox, J. S. Twenty-six-year results after Broström procedure for chronic lateral ankle instability. Am. J. Sports Med. 34, 975-978 (2006).

2. Viens, N. A., Wijdicks, C. A., Campbell, K. J., Laprade, R. F. \& Clanton, T. O. Anterior talofibular ligament ruptures, part 1: biomechanical comparison of augmented Broström repair techniques with the intact anterior talofibular ligament. Am. J. Sports Med. 42, 405-411 (2014).

3. Yeung, M. S., Chan, K. M., So, C. H. \& Yuan, W. Y. An epidemiological survey on ankle sprain. Br. J. Sports Med. 28, 112-116 (1994).

4. Martin, R. L., Davenport, T. E., Paulseth, S., Wukich, D. K. \& Godges, J. J. Ankle stability and movement coordination impairments: ankle ligament sprains. J. Orthop. Sports Phys. Ther. 43, A1-40 (2013).

5. Hertel, J. Functional anatomy, pathomechanics, and pathophysiology of lateral ankle instability. J Athl Train 37, 364-375 (2002).

6. Hertel, J. Sensorimotor deficits with ankle sprains and chronic ankle instability. Clin. Sports Med. 27, 353-370, vii (2008).

7. Arnold, B. L., De La Motte, S., Linens, S. \& Ross, S. E. Ankle instability is associated with balance impairments: a meta-analysis. Med. Sci. Sports Exerc. 41, 1048-1062 (2009).

8. Lee, J. H., Lee, S. H., Choi, G. W., Jung, H. W. \& Jang, W. Y. Individuals with recurrent ankle sprain demonstrate postural instability and neuromuscular control deficits in unaffected side. Knee Surg. Sports Traumatol. Arthrosc. 28, 184-192 (2020).

9. Lee, J. H., Lee, S. H., Jung, H. W. \& Jang, W. Y. Modified Broström procedure in patients with chronic ankle instability is superior to conservative treatment in terms of muscle endurance and postural stability. Knee Surg. Sports Traumatol. Arthrosc. 28, 93-99 (2020).

10. Munn, J., Sullivan, S. J. \& Schneiders, A. G. Evidence of sensorimotor deficits in functional ankle instability: a systematic review with meta-analysis. J. Sci. Med. Sport 13, 2-12 (2010).

11. Ross, S. E. \& Guskiewicz, K. M. Examination of static and dynamic postural stability in individuals with functionally stable and unstable ankles. Clin. J. Sport Med. 14, 332-338 (2004).

12. Zhang, L., Lu, J., Cai, B., Fan, S. \& Jiang, X. Quantitative assessments of static and dynamic balance performance in patients with chronic ankle instability. Medicine (Baltimore) 99, e19775 (2020).

13. Chen, H., Li, H. Y., Zhang, J., Hua, Y. H. \& Chen, S. Y. Difference in postural control between patients with functional and mechanical ankle instability. Foot Ankle Int. 35, 1068-1074 (2014).

14. Wilkerson, G.B. \& Nitz, A.J. Dynamic ankle stability: mechanical and neuromuscular interrelationships. 3, 43-57 (1994).

15. Park, Y. H., Park, S. H., Kim, S. H., Choi, G. W. \& Kim, H. J. Relationship between isokinetic muscle strength and functional tests in chronic ankle instability. J. Foot Ankle Surg. 58, 1187-1191 (2019).

16. Silbernagel, K. G., Steele, R. \& Manal, K. Deficits in heel-rise height and achilles tendon elongation occur in patients recovering from an Achilles tendon rupture. Am. J. Sports Med. 40, 1564-1571 (2012).

17. Silbernagel, K. G., Nilsson-Helander, K., Thomeé, R., Eriksson, B. I. \& Karlsson, J. A new measurement of heel-rise endurance with the ability to detect functional deficits in patients with Achilles tendon rupture. Knee Surg. Sports Traumatol. Arthrosc. 18, 258-264 (2010).

18. Möller, M., Lind, K., Movin, T. \& Karlsson, J. Calf muscle function after Achilles tendon rupture. A prospective, randomised study comparing surgical and non-surgical treatment. Scand. J. Med. Sci. Sports 12, 9-16 (2002).

19. Sman, A.D. et al. Design and reliability of a novel heel rise test measuring device for plantarflexion endurance. BioMed Res Int. ernational 2014, 391646 (2014).

20. Anandacoomarasamy, A. \& Barnsley, L. Long term outcomes of inversion ankle injuries. Br. J. Sports Med. 39, e14; discussion e14 (2005).

21. Delahunt, E. et al. Inclusion criteria when investigating insufficiencies in chronic ankle instability. Med. Sci. Sports Exerc. 42, 2106-2121 (2010).

22. Brorsson, A. et al. Recovery of calf muscle endurance 3 months after an Achilles tendon rupture. Scand. J. Med. Sci. Sports 26, 844-853 (2016).

23. Assal, M. et al. Limited open repair of Achilles tendon ruptures: a technique with a new instrument and findings of a prospective multicenter study. J. Bone Joint Surg. Am. 84, 161-170 (2002).

24. Cohen, J. Statistical power analysis for the behavioral sciences (Academic press, 2013).

25. McKeon, P. O. \& Hertel, J. Systematic review of postural control and lateral ankle instability, part I: can deficits be detected with instrumented testing. J Athl Train 43, 293-304 (2008). 
26. Medina McKeon, J.M. \& Hoch, M.C. The Ankle-Joint Complex: A Kinesiologic approach to lateral ankle sprains. J Athl Train 54, 589-602 (2019).

27. Delahunt, E., Monaghan, K. \& Caulfield, B. Changes in lower limb kinematics, kinetics, and muscle activity in subjects with functional instability of the ankle joint during a single leg drop jump. J. Orthop. Res. 24, 1991-2000 (2006).

28. Colby, S.M., Hintermeister, R.A., Torry, M.R. \& Steadman, J.R. Lower limb stability with ACL impairment. J. Orthop. Sports Phys. Ther. 29, 444-451; discussion 452-444 (1999).

29. Hiller, C. E. et al. Characteristics of people with recurrent ankle sprains: a systematic review with meta-analysis. Br. J. Sports Med. 45, 660-672 (2011).

30. Lunsford, B. R. \& Perry, J. The standing heel-rise test for ankle plantar flexion: criterion for normal. Phys. Ther. 75, 694-698 (1995).

31. Lee, J.H. \& Yoon, T.L. Effective treatment for chronic ankle instability during lateral step-down-kinesiology tape, resistance exercise, or both accompanied with heel raise-lower exercise? J Sport Rehabil, 1-8 (2019).

32. Lin, C. W., Delahunt, E. \& King, E. Neuromuscular training for chronic ankle instability. Phys. Ther. 92, 987-991 (2012).

33. Tabrizi, P., McIntyre, W. M., Quesnel, M. B. \& Howard, A. W. Limited dorsiflexion predisposes to injuries of the ankle in children. J. Bone Joint Surg. Br. 82, 1103-1106 (2000).

34. Vitale, T. D. \& Fallat, L. M. Lateral ankle sprains: evaluation and treatment. J. Foot Surg. 27, 248-258 (1988).

35. Konradsen, L. \& Ravn, J. B. Prolonged peroneal reaction time in ankle instability. Int. J. Sports Med. 12, 290-292 (1991).

36. Matsusaka, N., Yokoyama, S., Tsurusaki, T., Inokuchi, S. \& Okita, M. Effect of ankle disk training combined with tactile stimulation to the leg and foot on functional instability of the ankle. Am. J. Sports Med. 29, 25-30 (2001)

37. Rozzi, S. L., Lephart, S. M., Sterner, R. \& Kuligowski, L. Balance training for persons with functionally unstable ankles. J. Orthop. Sports Phys. Ther. 29, 478-486 (1999).

38. Kibler, W. B., Press, J. \& Sciascia, A. The role of core stability in athletic function. Sports Med. 36, 189-198 (2006).

39. Adlerton, A. K. \& Moritz, U. Does calf-muscle fatigue affect standing balance?. Scand. J. Med. Sci. Sports 6, 211-215 (1996).

40. Yaggie, J. A. \& McGregor, S. J. Effects of isokinetic ankle fatigue on the maintenance of balance and postural limits. Arch. Phys. Med. Rehabil. 83, 224-228 (2002).

41. Hubbard, T. J., Kramer, L. C., Denegar, C. R. \& Hertel, J. Contributing factors to chronic ankle instability. Foot Ankle Int. 28, 343-354 (2007)

\section{Acknowledgements}

This work was supported by the Korea Medical Device Development Fund grant funded by the Korean government (the Ministry of Science and ICT, the Ministry of Trade, Industry and Energy, the Ministry of Health \& Welfare, the Ministry of Food and Drug Safety) (KMDF_PR_20200901_0039, KMDF_PR_20200901_0131, KMDF_PR_20200901_0293). This work was supported by Institute for Information \& Communications Technology Promotion (IITP) grant funded by the Korean government (MSIT) (No.2019-0-00418, 3D Printing for Family Health Based on Real-life Smart Insoles Manufactured and Consistent System Development).

\section{Author contributions}

JHL and WYJ collected and analyzed the patient clinical data. JHL, HWJ, TSJ, and WYJ interpreted the data and were major contributors in writing the manuscript. All authors have read and approved the final manuscript.

\section{Competing interests}

The authors declare no competing interests.

\section{Additional information}

Correspondence and requests for materials should be addressed to W.Y.J.

Reprints and permissions information is available at www.nature.com/reprints.

Publisher's note Springer Nature remains neutral with regard to jurisdictional claims in published maps and institutional affiliations.

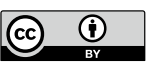

Open Access This article is licensed under a Creative Commons Attribution 4.0 International License, which permits use, sharing, adaptation, distribution and reproduction in any medium or format, as long as you give appropriate credit to the original author(s) and the source, provide a link to the Creative Commons licence, and indicate if changes were made. The images or other third party material in this article are included in the article's Creative Commons licence, unless indicated otherwise in a credit line to the material. If material is not included in the article's Creative Commons licence and your intended use is not permitted by statutory regulation or exceeds the permitted use, you will need to obtain permission directly from the copyright holder. To view a copy of this licence, visit http://creativecommons.org/licenses/by/4.0/.

(c) The Author(s) 2021 